\title{
The ecological impacts of marine debris: unraveling the demonstrated evidence from what is perceived
}

\author{
Chelsea M. Rochman, ${ }^{1,9}$ Mark Anthony Browne, ${ }^{2,3}$ A. J. Underwood,${ }^{4}$ Jan A. van Franeker, ${ }^{5}$ \\ Richard C. Thompson, ${ }^{6}$ And Linda A. Amaral-Zettller ${ }^{7,8}$ \\ ${ }^{1}$ Aquatic Health Program, School of Veterinary Medicine, University of California, Davis, California 95616, USA \\ ${ }^{2}$ National Center for Ecological Analysis and Synthesis, University of California, Santa Barbara, California 93101, USA \\ ${ }^{3}$ Evolution \& Ecology Research Centre, School of Biological, Earth and Environmental Sciences, University of New South Wales, \\ Sydney, NSW 2052, Australia \\ ${ }^{4}$ Centre For Research on Ecological Impacts of Coastal Cities, A11 School of Biological Sciences, University of Sydney, Sydney, \\ NSW 2006, Australia \\ ${ }^{5}$ Institute for Marine Research and Ecosystem Studies IMARES, 1797SH, Texel, 1780 AB Den Helder, The Netherlands \\ ${ }^{6}$ Marine Biology and Ecology Research Centre, School of Marine Science and Engineering, Plymouth University, Plymouth, \\ PL4 8AA, United Kingdom \\ ${ }^{7}$ Marine Biological Laboratory, Josephine Bay Paul Center for Comparative Molecular Biology and Evolution, Woods Hole, \\ Massachusetts 02543, USA \\ ${ }^{8}$ Department of Earth, Environmental and Planetary Sciences, Brown University, Providence, Rhode Island 02912, USA
}

Abstract. Anthropogenic debris contaminates marine habitats globally, leading to several perceived ecological impacts. Here, we critically and systematically review the literature regarding impacts of debris from several scientific fields to understand the weight of evidence regarding the ecological impacts of marine debris. We quantified perceived and demonstrated impacts across several levels of biological organization that make up the ecosystem and found 366 perceived threats of debris across all levels. Two hundred and ninety-six of these perceived threats were tested, $83 \%$ of which were demonstrated. The majority $(82 \%)$ of demonstrated impacts were due to plastic, relative to other materials (e.g., metals, glass) and largely $(89 \%)$ at suborganismal levels (e.g., molecular, cellular, tissue). The remaining impacts, demonstrated at higher levels of organization (i.e., death to individual organisms, changes in assemblages), were largely due to plastic marine debris (>1 mm; e.g., rope, straws, and fragments). Thus, we show evidence of ecological impacts from marine debris, but conclude that the quantity and quality of research requires improvement to allow the risk of ecological impacts of marine debris to be determined with precision. Still, our systematic review suggests that sufficient evidence exists for decision makers to begin to mitigate problematic plastic debris now, to avoid risk of irreversible harm.

Key words: assemblage; biological organization; ecology; plastic debris; population; systematic review.

\section{INTRODUCTION}

Under existing legislation, materials are not considered hazardous unless research demonstrates with certainty that a material harms humans, wildlife, and/ or the environment (Inter-Departmental Liaison Group on Risk Assessment 2002, Official Journal of the

Manuscript received 29 October 2014; revised 28 May 2015; accepted 17 August 2015. Corresponding Editor: P. T. Raimondi.

${ }^{9}$ E-mail: cmrochman@ucdavis.edu
European Union 2008 ). If classified hazardous, existing laws can be used to help eliminate sources, rehabilitate habitats, find safer alternative products (Rochman et al. 2013a) and/or shift the burden of proof towards the manufacturer to demonstrate safety (EU 52000DC0001 Inter-Departmental Liaison Group on Risk Assessment 2002). For marine debris, decision makers have been unable to use existing laws to mitigate contamination because they are uncertain about the nature and extent of the risk of marine debris to humans and the ecosystem. This lack of understanding is surprising because 
peer-reviewed literature describing marine debris has grown substantially since the turn of the century. A search of the literature in Web of Science for the key words "marine debris" and "plastic debris" shows that the number of studies published annually has doubled since the year 2000. In the year 2000, 65 and 85 studies, respectively, were published and in 2013, 129 and 182 studies, respectively, were published. This large increase in scientific literature probably reflects a growing concern that marine debris is hazardous and requires appropriate responses.

Contamination of habitats and organisms by marine debris is now globally ubiquitous (Thompson et al. 2009) with no signs that environmental accumulations are decreasing (Thompson et al. 2004, Law et al. 2010). Debris contaminates a diversity of habitats, including shorelines (Browne et al. 2015a), coral reefs (Donohue et al. 2001), shallow bays (Endo et al. 2005, Ashton et al. 2010), estuaries (Browne et al. 2010), the open ocean (Carpenter and Smith 1972, Cózar et al. 2014) and the deep sea (Goldberg 1997, Galgani et al. 2000). Exposure of organisms to marine debris causes concern, and the quantity, frequency of occurrence, type, and size of debris may all determine the consequences to wildlife, and ultimately, the ecosystem. Contamination in the form of entanglement and ingestion is recorded in tens of thousands of individual animals (Gall and Thompson 2015) and at least 558 species, including all known species of sea turtles, $66 \%$ of all species of marine mammals, and $50 \%$ of all species of seabirds (Kühn et al. 2015). In some species, ingestion is reported in over $80 \%$ of a population sampled (e.g., Murray and Cowie 2011, van Franeker et al. 2011). Moreover, marine debris hosts microbial assemblages distinct from surrounding seawater through the creation of novel habitat (Zettler et al. 2013).

Scientists, industry, and government are in agreement that marine debris is a global environmental issue, contaminating habitats and wildlife from the poles to the equator (Thompson et al. 2009, Sutherland et al. 2010, Browne et al. 2015a, Gall and Thompson 2015). Now, scientists and policy makers aim to understand the ecological impacts of this debris on the biosphere. There can be no doubt that marine debris poses several potential threats. It may be hazardous to wildlife physically, by entanglement and ingestion, or via alteration of habitat and/or transport of nonnative and potentially pathogenic species (i.e., acting as potential fomites; Gregory 2009, Zettler et al. 2013). It can also be hazardous to wildlife chemically, if chemical constituents of the debris itself (i.e., incorporated during manufacture) or environmental chemicals (i.e., organic and metal pollutants sorbed from the surrounding environment) are transferred to the tissues of organisms upon direct ingestion of plastic or via the food web (Browne et al. 2013, Rochman et al. 2013b, Tanaka et al. 2013). It may even be hazardous to humans because small particles of debris, demonstrated to bioaccumulate in tissues of animals (Browne et al. 2008), are present in a range of commercially important fish and shellfish (Choy and Drazen 2013, Van Cauwenberghe and Janssen 2014). Although there is considerable evidence of harmful effects on individual organisms and seemingly many perceived threats to populations, assemblages and species, there is currently little knowledge or agreement regarding whether such potential threats are demonstrated ecologically relevant impacts, affecting wildlife at higher levels of biological organization.

Here, we aim to understand the weight of the evidence regarding perceived and demonstrated impacts and whether existing published data demonstrates ecological effects of marine debris. For several environmental stressors, including marine debris, effects are shown at one or several different lower levels of organization (e.g., molecular, cellular, organism; Underwood and Peterson 1988, Adams et al. 1989). Although ecological impacts are generally considered those relevant to populations, assemblages, and species, understanding responses at these lower levels of organization can provide insight into causal relationships between stressors and their effects at ecological levels (Adams et al. 1989, Browne et al. 2015b). As such, we examined the evidence across several levels. Moreover, because other types of debris (e.g., terrestrial, atmospheric, and medical) are the same type, shape, and size and likely behave similarly to marine debris, we examined the literature for impacts from debris, in general, to gain further insight into how marine debris may impact marine organisms.

Several narrative reviews provide useful information regarding the historical developments about the extent to which organisms are contaminated with debris. Yet, these provide (1) limited information to demonstrate biological, and especially ecological, impacts, and (2) no systematic and critical assessment of the quality, quantity, and level of uncertainty of evidence about these impacts. To evaluate the weight of evidence regarding the ecological impacts of marine debris, we systematically and critically reviewed relevant literature regarding effects of debris at several levels of biological organization, spanning the fields of medicine, biological oceanography, conservation biology, toxicology, and ecology, asking two questions: (1) What are the perceived threats? and (2) What are the demonstrated impacts of debris?

\section{Methods}

\section{Literature review}

We systematically reviewed the literature regarding contamination (i.e., the presence of debris) and pollution (i.e., a biological response to debris) associated with debris, to determine the perceived, tested, and 
demonstrated impacts of marine debris to marine life. We searched the literature using Web of Knowledge, Science Direct, and Scopus for the key word terms: "marine debris" and "plastic debris" from all available years for each database (1898, 1823 and 1990, respectively) through 2013. In addition, we examined the journals of Marine Pollution Bulletin and Environmental Science \& Technology for these key words individually because of their publication record regarding this topic. Our literature search resulted in a collection of literature spanning the fields of medicine, oceanography, conservation and marine biology, toxicology, and ecology. We chose to examine studies across a broad range of disciplines to gather knowledge regarding the effects of debris in general. Thus, all papers discussing impacts relevant to marine debris, including studies regarding medical, terrestrial, and atmospheric debris, were included in our systematic review.

\section{Data extraction and quality assessment}

Two individuals from our group first assessed publications for relevance to our objective based upon the title and abstract, then further reviewed these for relevance to impacts (see Appendix S1 for a list of references). Any discrepancy was discussed among coauthors of this paper. For each relevant publication, we examined perceived and demonstrated effects of debris at 14 levels of biological organization: subatomic particle, atom, small molecule, macromolecule, molecular assemblage, organelle, cell, tissue, organ, organ system, organism, population, species, and assemblage. There were no studies discussing impacts to a species, so we only report findings from 13 levels. We then categorized each paper according to the levels of organization discussed and sorted them into the following broader categories: suborganismal, organismal, and ecologically relevant levels (population and assemblage). All publications that were included were assigned to coauthors of this paper for data extraction. Where appropriate, we recorded information regarding the source of the material (i.e., gray literature, conference proceeding, peer-reviewed paper with original data, peer-reviewed paper with no original data), characterization of the affected area (i.e., location of study, type of area studied: habitat, organism, cell, etc.), the pattern and/or perceived threat determined, source of data (i.e., anecdotal, qualitative description, quantitative, correlative, experimental), characteristics of debris (i.e., shape, size, type, whether the type of material was identified using appropriate methods), logic and interpretation (i.e., clarity, closeness of fit to hypotheses), experimental design (i.e., use of controls, environmental relevance of exposures) and statistical analyses (i.e., appropriateness of tests, statistics done appropriately). Those who synthesized the data returned to each paper to confirm the data that was extracted before including it in analysis. Any discrepancy was discussed among coauthors to reach an agreement, which occurred for fewer than 10 publications in total. In addition, all data was revisited to assure numbers within the spreadsheet, figures, and tables matched. Errors, such as typos or mathematical errors, were fixed and were never found to change our overall results by more than $5 \%$. Fig. 1 summarizes this process (see Appendix S1 for the detailed protocol).

\section{Synthesis of data}

We only used primary literature and excluded nonoriginal data from review papers. We synthesized perceived (i.e., hypothesized in or described by extrapolation from the data presented within or from other studies), tested and demonstrated impacts of debris across each level of organization in increasing order of ecological relevance using an established framework for pollutants (Adams et al. 1989).

For each study, we recorded the size of debris, the level of biological organization, whether the impact was solely perceived, tested, or demonstrated and the nature of the impact. For many papers, impacts were discussed at multiple levels of biological organization and sizes of debris. Each impact, from

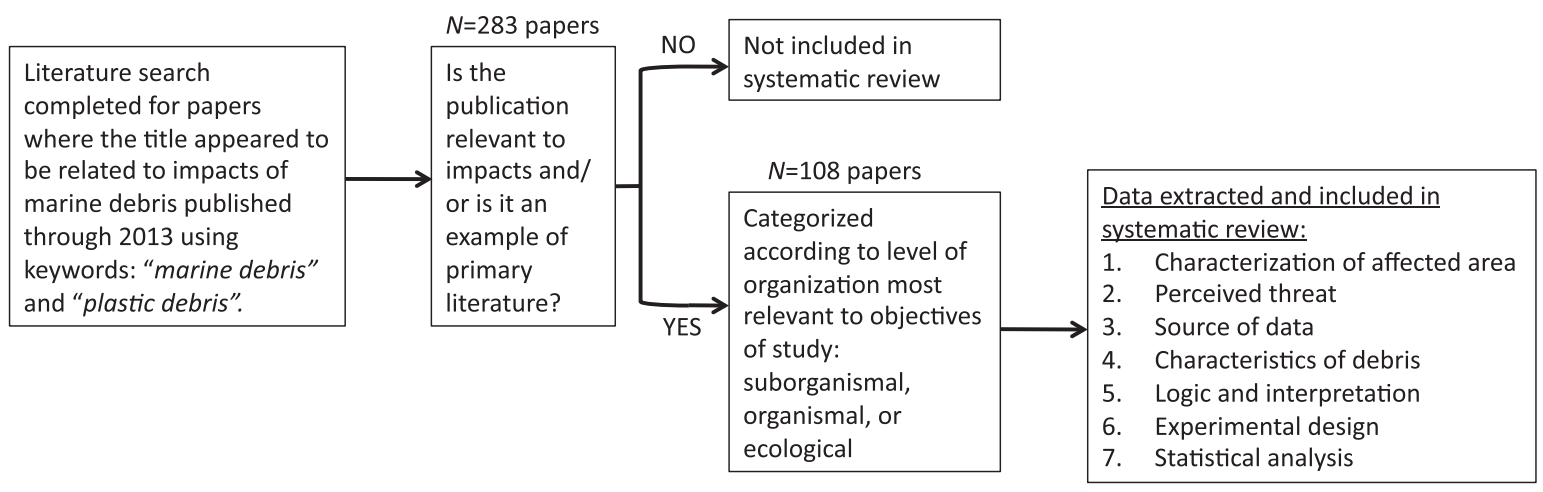

FIG. 1. A schematic representation of our literature selection and a decision-making tree for extraction of data for this review. 
each size of debris at each level of biological organization, were accounted for individually and plotted on a matrix depicting the magnitude of total impacts at each level of biological organization as a function of the size of debris, ranging from $1 \mathrm{~nm}$ (e.g., nanomaterial) to $1 \mathrm{~km}$ (e.g., fishing net) (Fig. 2). All perceived impacts are depicted in Fig. 2a, those that were tested in Fig. $2 \mathrm{~b}$ and impacts that were both tested and demonstrated in Fig. 2c.

Several studies made assumptions about how contamination by debris may be harming wildlife or how an effect at one level of organization will affect the organism at a higher level of organization. Such studies do not demonstrate an impact and thus are depicted only in the matrix of perceived impacts (Fig. 2a). We did not consider correlative evidence to have demonstrated an impact with the same level of confidence as experimental evidence, because any correlation of an impact with an amount or type of debris could be due to other causes and not the debris itself (Goodsell et al. 2009). As such, where there was correlative evidence, it is depicted with a diamond symbol among the demonstrated experimental evidence (Fig. 2c) and was not included in calculations for the quantity of demonstrated impacts caused by debris (Table 1). Some studies were not properly controlled, used environmentally unrealistic or irrelevant exposures and/or lacked proper statistical procedures or interpretations. These could not be considered to have demonstrated an impact where the difficulties of the study compromised or confounded any interpretation and thus were included as tested but not as demonstrated. See Appendix S1: Tables S1, S2, and S3 for lists of studies included in Fig. 2 and rationale for inclusion in a, b, and/or c respectively and Appendix S1: Table S4 for a list of studies not included in Fig. 2 and rationale for not including them).

Because our objective was to evaluate the weight of evidence regarding ecological impacts, we highlighted studies that included impacts from debris at the highest levels of organization (organismal and the ecologically relevant levels of population and assemblage; i.e., in the top three rows of Fig. 2). These are depicted in a separate figure (Fig. 3), considering an impact undeniably demonstrated when the observed effect could only have been caused by the debris. We classified effects as (1) organism (an individual organism's death was a direct result of debris), (2) population (population size changed as a result of debris), and (3) assemblage (there was a change in the structure or composition of assemblages as a direct result of debris). All studies discussing effects at these levels were revisited by two coauthors to determine whether (1) no effect had been suggested, (2) an effect had been perceived but not tested and demonstrated, (3) an effect was tested and the results explicitly did not show any effect, or (4) where an effect had been perceived, tested, and demonstrated.

\section{RESULTS}

\section{Perceived impacts}

The reviewed literature shows that scientists perceive hundreds of impacts from debris across all levels of organization, from subatomic to assemblage (Fig. 2a). In total, there were 366 cases of perceived impacts due
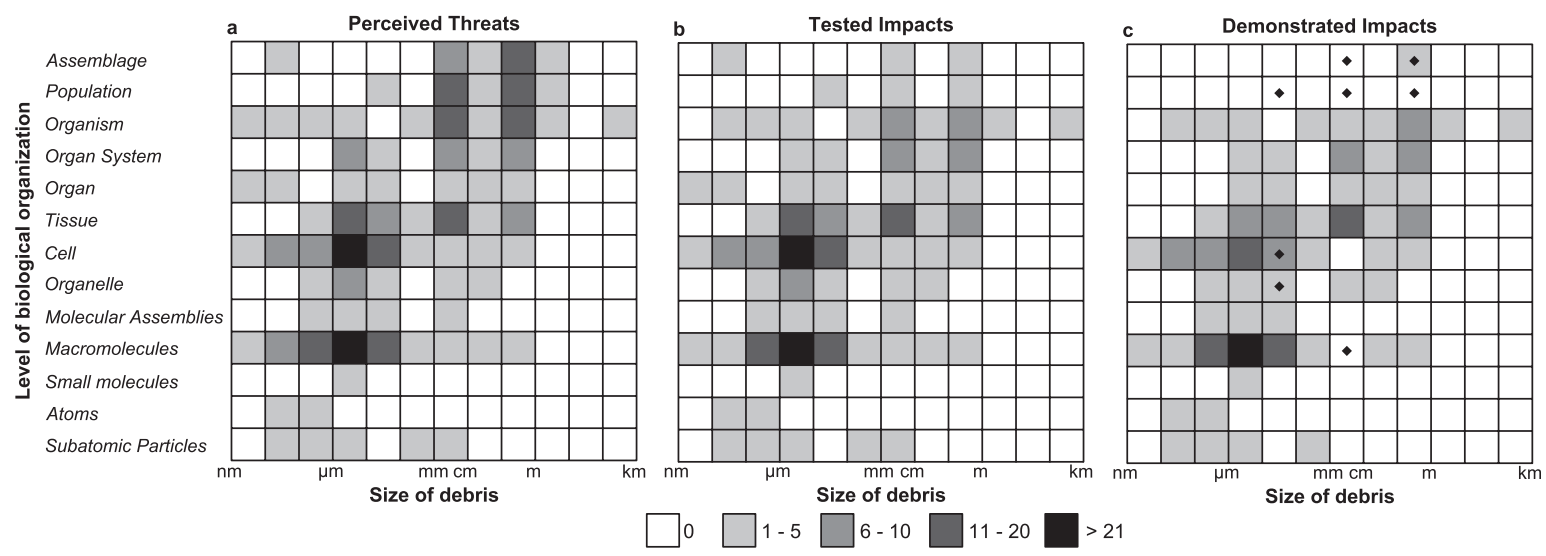

FIG. 2. Perceived, tested, and demonstrated impacts of debris. Rows in each matrix represent different levels of biological organization from subatomic particles, atoms, small molecules, macromolecules, molecular assemblies, organelle, cell, tissue, organ, organ system, organism, and population to assemblage. Columns represent order-of-magnitude sizes of debris from smallest (left) to largest (right). Shading in the individual cells of the matrix represent the magnitude of (a) perceived, (b) tested, and (c) demonstrated impacts of debris in peer-reviewed literature identified using the search terms plastic debris and marine debris. Shading represents the number of impacts. Diamonds in the matrix in panel (c) correspond to cells where at least one impact has been demonstrated by correlative evidence. All impacts described at multiple size ranges and levels of biological organization are represented such that there are more impacts than there are papers. 
to debris composed of several materials. Overall, perceived impacts from plastic marine debris overwhelmed cases due to other types of debris, a trend that is consistent with relative amounts of debris found in marine habitats (Barnes et al. 2009). Eighty seven percent of described perceived impacts included an association with plastic, $21 \%$ with metal, $2 \%$ wood, and $<1 \%$ glass. To organize our results, we discuss perceived impacts from debris according to size; debris $>1 \mathrm{~mm}$ (hereafter called macrodebris) and debris $<1 \mathrm{~mm}$ (hereafter called microdebris) as in Browne et al. (2010).

Overall, 58\% (211 of the 366 cases) of perceived impacts were associated with microdebris composed of only two types of materials, $77 \%$ plastic and $25 \%$ metal (note some studies perceived effects from both metal and plastic). Studies about impacts from microdebris in marine habitats were scarce. Only $15 \%$ of perceived impacts for microdebris were about marine debris. The remaining studies were from literature researching the impacts of medical debris (debris originating from implanted medical devices; $72 \%$ ), nanomaterials $(7 \%$, although sometimes involving their impacts in aquatic habitats), and atmospheric debris $(6 \%)$, all relevant to marine debris according to size, type, and route of exposure. Moreover, for microdebris, the majority of perceived impacts $(93 \%)$ were suborganismal, with many suggesting changes in the structure and functions of macromolecules and cells from medical debris and inhalation/ingestion of small particles. See Table 1 for a list of perceived impacts within each level of organization.
The remaining $42 \%$ (155 of 366 cases) of all perceived impacts were about macrodebris. Perceived impacts from macrodebris were related to four types of materials: $99 \%$ of studies discussed plastic, $15 \%$ metal, $5 \%$ woody debris, and $1 \%$ glass. In contrast to microdebris, the majority $(87 \%)$ of concerns about macrodebris were about marine debris. Macrodebris in marine habitats has been studied for decades (Laist 1987). The remainder was from literature discussing the impacts of medical debris $(5 \%)$ and terrestrial debris $(8 \%)$. Unlike microdebris, the majority of concerns $(58 \%)$ for macrodebris were potential impacts to individual organisms (i.e., death) and/or ecological impacts to populations and assemblages. These perceived impacts were relatively evenly distributed across these higher levels of organization and were generally due to ingestion, entanglement, and the transport of nonnative species. See Table 1 for a breakdown of perceived impacts within each level of organization.

\section{Demonstrated impacts}

Of the 366 perceived impacts, 296 (81\%) were from studies that tested hypotheses. The remaining were impacts extrapolated or theorized within the discussion of the manuscript regarding how their findings might lead to harmful effects to organisms or how an impact at one level of organization may lead to an effect at a higher level of organization. Of the perceived impacts that were tested, $245(83 \%)$ were demonstrated using non-correlative experimental evidence and $15(5 \%)$ were

Table 1. Breakdown of perceived and demonstrated impacts from micro- and macro-debris at each level of biological organization.

\begin{tabular}{|c|c|c|c|c|}
\hline \multirow[b]{2}{*}{ Impacts } & \multicolumn{2}{|c|}{ Perceived } & \multicolumn{2}{|c|}{ Demonstrated } \\
\hline & Micro & Macro & Micro & Macro \\
\hline No. of cases & 366 & & 245 & \\
\hline Size $(\mathrm{mm})$ & $<1$ & $>1$ & $<1$ & $>1$ \\
\hline Percentage & 58 & 42 & 71 & 29 \\
\hline No. cases & 211 & 155 & 175 & 70 \\
\hline \multicolumn{5}{|l|}{ No. cases at each level of biological organization } \\
\hline \multicolumn{5}{|l|}{ Suborganismal } \\
\hline Subatomic (e.g., oxidative stress) & 9 & 1 & 7 & 0 \\
\hline Atomic (e.g., greater concentrations of intracellular calcium) & 2 & 0 & 2 & 0 \\
\hline Small molecules (e.g., toxic metabolites) & 4 & 0 & 4 & 0 \\
\hline Macromolecules (e.g., protein, DNA damage) & 67 & 3 & 60 & 2 \\
\hline Molecular assemblies (e.g., formation of protein chains) & 7 & 2 & 6 & 0 \\
\hline Organelles (e.g., more micronuclei) & 12 & 4 & 7 & 2 \\
\hline Cells (e.g., necrosis, less viable cells) & 56 & 5 & 45 & 3 \\
\hline Tissues (e.g., inflammation, lacerations observed) & 25 & 25 & 29 & 22 \\
\hline Organs (e.g., change in size, lesions) & 8 & 5 & 6 & 3 \\
\hline Organ system (e.g., poorly functioning digestive system) & 7 & 20 & 5 & 16 \\
\hline \multicolumn{5}{|l|}{ Organismal } \\
\hline Organism (i.e., death to an individual) & 11 & 34 & 4 & 20 \\
\hline \multicolumn{5}{|l|}{ Ecological } \\
\hline Populations (e.g., increase or decrease in size of population) & 1 & 29 & 0 & 0 \\
\hline Assemblages (e.g., change in abundance or diversity of biota) & 2 & 27 & 0 & 2 \\
\hline
\end{tabular}

Note: Demonstrated impacts do not include those where evidence was correlative. 
a
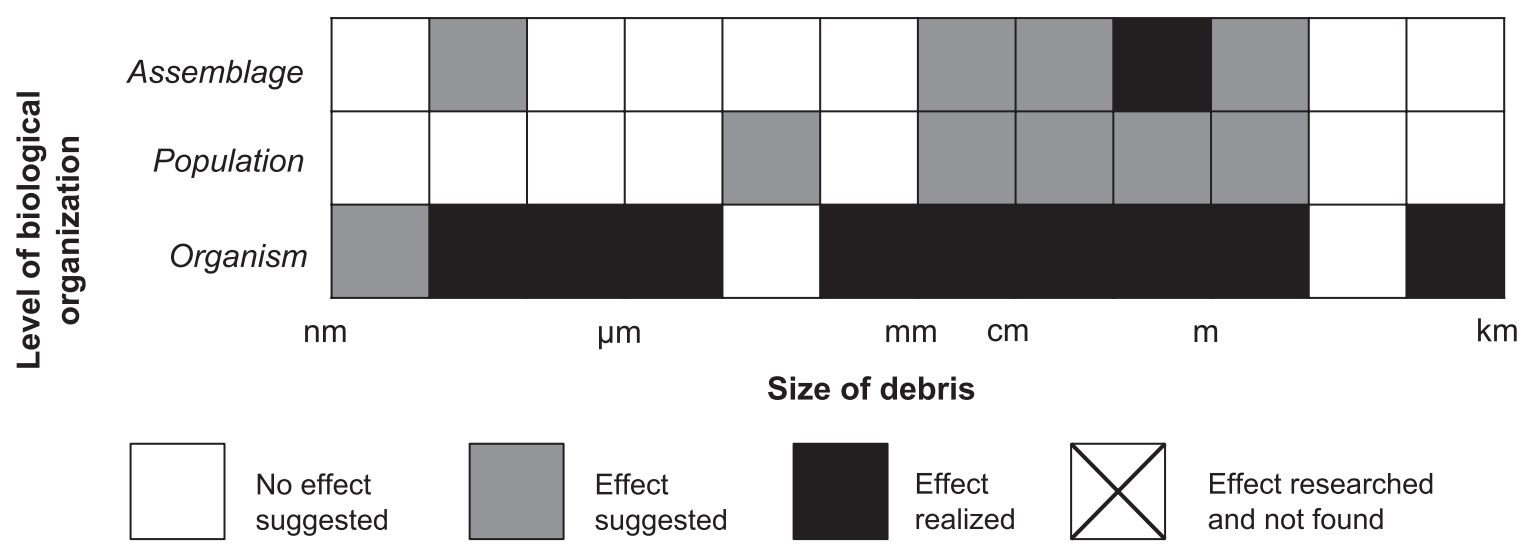

b

\begin{tabular}{|c|c|c|c|}
\hline Reference Cited & Level of Organization & Size Range & Cause of Impact \\
\hline Beck and Barros Mar. Pollut. Bull. 1991, 22, 508-510. & Organism & $100 \mathrm{~mm}-10 \mathrm{~m}$ & ingestion \\
\hline Bjorndal et. al. Mar. Pollut. Bull. 1994, 28, 154-158. & Organism & $1 \mathrm{~mm}-1 \mathrm{~m}$ & ingestion \\
\hline Brandao et al. Mar. Pollut. Bull. 2011, 62, 2246-2249. & Organism & $10 \mathrm{~mm}-1 \mathrm{~m}$ & ingestion \\
\hline Browne et al. Curr. Biol. 2013, 23, 2388-2392. & Organism & $100 \mu \mathrm{m}-1 \mathrm{~mm}$ & ingestion \\
\hline Bugoni et al. Mar. Pollut. Bull. 2001, 42, 1330-1334. & Organism & $10 \mathrm{~mm}-100 \mathrm{~mm}$ & ingestion \\
\hline de Stephanis et al. Mar. Pollut. Bull. 2013, 69, 206-214. & Organism & $100 \mathrm{~mm}-1 \mathrm{~m}$ & ingestion \\
\hline Fowler et al. Mar. Pollut. Bull. 1987, 18, 326-335. & Organism & $1 \mathrm{~mm}-1 \mathrm{~m}$ & entanglement \\
\hline Gilardi et al. Mar. Pollut. Bull. 2009, 60, 376-382. & Organism & $1 \mathrm{~m}-10 \mathrm{~m}$ & entanglement \\
\hline Good et al. Mar. Pollut. Bull. 2010, 60, 39-50. & Organism & $100 \mathrm{~m}-1 \mathrm{~km}$ & entanglement \\
\hline Jacobsen et al. Mar. Pollut. Bull. 2010, 60, 765-767. & Organism & $1 \mathrm{~mm}-1 \mathrm{~m}$ & ingestion \\
\hline Lee et al. Environ. Sci. Technol. 2013, 47, 11278-11283. & Organism & $10 \mathrm{~nm}-10 \mu \mathrm{m}$ & ingestion \\
\hline Moore et al. Mar. Pollut. Bull. 2009, 58, 1045-1051. & Organism & $1 \mathrm{~mm}-1 \mathrm{~m}$ & entanglement \\
\hline Udyawer et al. Mar. Pollut. Bull. 2013, 73, 336-338. & Organism & $10 \mathrm{~mm}-100 \mathrm{~mm}$ & entanglement \\
\hline Uhrin and Schellinger Mar. Pollut. Bull. 2011, 62, 2605-2610. & Organism & $100 \mathrm{~mm}-1 \mathrm{~m}$ & smothering \\
\hline Vélez-Rubio et al. Mar. Biol. 2013, 160, 2797-2811. & Organism & $10 \mathrm{~mm}-100 \mathrm{~mm}$ & ingestion \\
\hline Katsanevakis et al. Mar. Pollut. Bull. 2007, 54, 771-778. & Assemblage & $100 \mathrm{~mm}-1 \mathrm{~m}$ & addition of habitat \\
\hline Lewis et al. New Zeal J. Mar. Fresh. 2009, 43, 271-282. & Assemblage & $100 \mathrm{~mm}-1 \mathrm{~m}$ & smothering \\
\hline
\end{tabular}

FIG. 3. Demonstrated impacts of marine debris across higher levels of biological organization. (a) Rows represent levels of higher biological organization (organism, population, and assemblage). Columns represent order-of-magnitude sizes of debris from smallest (left) to largest (right). White boxes represent instances where no perceived effect was suggested. Gray boxes represent instances where literature suggested an effect but no effect has been demonstrated. Black boxes represent instances where literature reported a demonstrated effect (demonstrated effects do not include those where evidence was correlative). If an example had been found, a box with crossed lines would represent a study where a perceived effect was suggested, but could not be demonstrated. (b) References where demonstrated impacts were found, i.e., that were used to fill the boxes in black, are provided with the level of biological organization, the size range of the debris, and the cause of the impact.

demonstrated via correlative evidence (shown as diamonds in Fig. 2c). It is noteworthy that only one (Browne et al., 2008) of the remaining 12\% found that debris did not cause an effect. Rather, these remaining studies claimed to demonstrate an impact, but we could not accept that the impact had been demonstrated 
unambiguously because the studies lacked appropriate controls, used inappropriate statistical methods or misinterpreted their results. For example, some experiments did not include negative controls and thus could not determine if the impact was from the debris or from some other factor in their design. Other experiments used inappropriate statistical tests (e.g., a one-factor analysis when the study was clearly multifactorial). Some studies simply claimed to show an impact when there were no data to support this view.

Overall, the majority $(89 \%)$ of demonstrated impacts were at suborganismal levels of organization and the majority $(83 \%)$ were due to plastic debris. Of the demonstrated impacts at suborganismal levels of organization, $78 \%$ were due to microdebris and were solely caused by plastic $(74 \%)$ and metal $(28 \%)$ (note that some studies considered effects from plastic and metal). For microdebris, only $12 \%$ of the studies were related to marine debris while $70 \%$ were related to medical debris, $7 \%$ to nanomaterials (sometimes regarding their impacts in aquatic habitats), and $11 \%$ to atmospheric particulates. Impacts from microplastic at suborganismal levels were generally demonstrated via laboratory experiments and due to inhalation/ingestion or to wear debris from surgical materials. The remaining $22 \%$ of demonstrated impacts at suborganismal levels were caused by macrodebris, all due to plastic. Some studies included multiple types of debris and thus some of these impacts were also caused by metal $(24 \%)$, glass $(3 \%)$, and wood $(3 \%)$. In contrast to microdebris, $72 \%$ of demonstrated impacts from macrodebris were related to marine debris and the other $28 \%$ to terrestrial debris (e.g., plastic debris ingested by goats). Demonstrated effects from macrodebris at suborganismal levels were all due to entanglement and ingestion. See Table 1 for the biological levels at which suborganismal impacts were due to micro- and macro-debris. Such impacts at suborganismal levels are specific, related to a particular physiological mechanism and are considered less ecologically relevant (Adams et al. 1989).

At organismal and ecological (population and assemblage) levels of organization, evidence of demonstrated impacts relative to perceived threats was extremely sparse (Fig. 3). At these higher levels of biological organization, we found 26 examples of noncorrelative demonstrated effects in 17 published studies (Fig. 3). The majority of these effects were at the organismal level $(92 \%)$, demonstrating deaths of individuals due to debris. In fact, all demonstrated deaths of individual organisms were due to marine debris and demonstrated at nearly all sizes of debris examined (Fig. 3). The remaining $8 \%$ were impacts at levels considered ecologically relevant and were solely demonstrated for assemblages and due to marine debris.

In fact, all of the evidence for impacts at higher levels of organization (i.e., organism and above) came from studies testing hypotheses regarding the effects of marine debris, $85 \%$ of which examined effects of macrodebris. All of the impacts were due to plastic debris, and only two include impacts from metallic debris and two from glass debris. The most common items of marine debris reported to cause demonstrated effects at the organism or ecological levels were lost fishing gear (e.g., nets) and other items of plastic debris such as rope, bags, straws, and degraded fragments.

Of these demonstrated impacts on organisms, $63 \%$ of deaths were caused by ingestion, $29 \%$ by entanglement, and $8 \%$ by smothering. Demonstrated organismal effects from ingestion were reported for two species of marine mammals, one species of sea turtle, one species of seabird and two species of marine invertebrates. Demonstrated organismal effects from entanglement were reported for 27 species of fish, 10 species of marine mammals, 49 species of seabirds, 1 species of sea snake, and 75 species of marine invertebrates. Demonstrated organismal effects due to smothering were reported in one species of cord-grass, Spartina alterniflora, including the complete loss of vegetation in some cases (Uhrin and Schellinger 2011). Because many other species are associated with $S$. alterniflora, there may well be effects on the associated assemblage, but this was not examined.

We found two examples of demonstrated impacts to assemblages. One demonstrated the negative ecological impact of derelict fishing gear smothering a coral assemblage and causing the mortality of several species of corals and associated sessile fauna (Moore et al. 2009). The second study demonstrated an ecological effect whereby adding plastic bottles and glass jars to a soft sediment benthic habitat altered the assemblage of soft-bottom benthic organisms (Katsanevakis et al. 2007). They found more organisms and species where debris was added, possibly explained by the debris providing extra hard substratum for some species (including one species each of gastropod, ascidian, and sponge) and acting as a refuge for others (including one species of hermit crab; Katsanevakis et al. 2007).

\section{Discussion}

Our systematic review confirmed that there are many perceptions about how marine debris can cause harm in marine habitats (i.e., many cases of perceived impacts) across all levels of biological organization. Here, we show that many of these perceptions have been tested, and that in almost every case where an effect was properly tested an impact was demonstrated. Thus, we found substantial evidence of impacts caused by debris, including marine debris. Overall, we found numerous impacts at suborganismal levels, several at the organismal level demonstrating clear evidence that marine debris can be the cause of death in individual organisms and little at the ecological levels demonstrating that marine debris can alter assemblages.

While we found most evidence at suborganismal levels, it is not a foregone conclusion that sublethal effects 
and/or increased mortality due to debris will cause an ecological impact (the evidence of deaths of individuals observed here may suggest a hazard to substantial numbers of individuals, and therefore possibly to the population and/or assemblage). Furthermore, it is noteworthy that we narrowed the definition of an organismal effect to death, ignoring the fact that demonstrated sublethal impacts (e.g., reduction in mass, changes in behavior) on many individuals is often inferred to affect populations. To be sure that such an ecological response exists, requires a stronger weight of evidence at ecological levels or the establishment of clear linkages between impacts caused by debris at lower levels to ecological impacts (Browne et al. 2015b).

Thus, our findings do demonstrate impacts from marine debris, but also demonstrate that the quantity and quality of current research regarding ecological impacts of marine debris requires improvement before any clear general ecological conclusions could be reached. Due to the large amount of literature reviewed, it is not possible to provide details describing every scenario where impacts were demonstrated or not (see Appendix S1: Tables S1, S2, and S3 for detailed information regarding all studies included in our systematic review). Instead, below, we selected examples to illustrate the state of the present knowledge represented in the literature.

Several studies investigated environmental contamination caused by marine debris and discussed perceived ecological impacts, but did not measure any. For example, Carson et al. (2011) measured the permeability and thermal properties of the sand on beaches in experimental areas where they mixed sediments with specified amounts of plastic $(<10 \mathrm{~mm}$ in size). Experimental sediments increased water flow and warmed more slowly than did natural sediments (although these effects were only significant for plastics in large amounts, i.e., treatments with 10-20 times more plastic than found on average in the field). Thus, debris in large amounts can clearly alter physical attributes of sediments, which may, as pointed out by Carson et al. (2011), cause alterations to populations and assemblages or to reproduction and survival of individual animals in the sediments, but these were not examined.

Our systematic review found that for some studies (nine in total, two about marine debris and seven about medical debris), the perceived impact was not tested using well-designed experiments. For example, some studies simply did not test the hypotheses regarding effects that were discussed. Others used inappropriate designs or contained statistical errors and thus results were not interpreted correctly. Some failed to include a negative or procedural control making it impossible to determine if the observed effects were due to the debris or some other experimental factor. In such cases, the data were not sufficiently convincing for us to accept that an effect had been demonstrated.

In other cases, effects (including at the population and assemblage levels) were accepted as demonstrated, but with less confidence because experiments were correlative and thus difficult to interpret as conclusive. For example, Özdilek et al. (2006) found a negative correlation between amounts of debris on different parts of the Turkish coastline and the success of hatchling turtles (Chelonia mydas) reaching the sea. The authors attributed this to larger numbers of predatory ghost crabs where there was more debris, but also noted the limitations of their study in that the turtles and crabs could well have been affected by numerous environmental variables other than marine debris.

Several studies used experimental comparisons and demonstrated clear evidence of impacts, including at the higher levels of organism and/or assemblage. Uhrin and Schellinger (2011) tethered wire crab pots and, separately, tires in areas of saltmarsh, keeping areas with no attached debris as controls. After 9 or 13 weeks, there was a sustained decrease $(56 \%$ due to crab pots and $54 \%$ due to tires) in amounts of cordgrass, $S$. alterniflora, a species that forms habitat for many other organisms. While this study demonstrated organism-level effects, it did not demonstrate assemblage-level effects because no other organisms were sampled. Katsanevakis et al. (2007) demonstrated assemblage-level impacts by placing debris (12 plastic bottles and 4 glass jars in each plot, which was in the upper part of the range of amounts of litter found in the field) into $10 \times 10 \mathrm{~m}$ experimental plots of sediment at 16-20 m depth in coves on a Greek coast. Over one year, the numbers of species of benthic animals increased in plots with debris, compared with plots with no added debris, clearly demonstrating alterations of the composition of benthic assemblages due to marine debris.

Overall, we conclude that there is a pressing need for robust, quantitative information to predict ecological impacts to species of wildlife that are considerably contaminated with marine debris. The presence, sizes, frequencies, and nature of ecological impacts are currently largely unknown. There may be large-scale impacts that we are missing simply due to a failure to examine them. Testing hypotheses regarding ecological impacts has been sparse to date, especially in relation to microdebris in the marine environment. We found that there were not yet sufficient data to include a meta-analysis or risk assessment as part of our systematic review. Thus, we chose to quantify the weight of the evidence regarding perceived and demonstrated impacts caused by marine debris by reviewing the literature regarding impacts from debris in general. To assess the scale, magnitude and frequency of realized impacts due to marine debris, research investigating specific ecological questions is warranted. Future studies must use more experimental work where possible and better modeling of effects of mortality of individuals on the size of the population.

While we call for more conclusive evidence regarding ecological impacts from marine debris, it should be recognized that, for some species (particularly for 
megafauna) and/or scenarios, our lack of knowledge is not attributable to problems in experimental design or interpretation of results from published papers. Instead, the problem is attributed to logistics in sampling and/or a lack of knowledge of how the damage to or deaths of individuals might actually affect populations. For some marine mammals and seabirds, there are plenty of data to demonstrate that the addition of debris to their habitats causes contamination of marine life via ingestion or entanglement. Still, there is little evidence for this contamination being the cause of any ecological harm. Ingestion of plastic has been reported in as many as $95 \%$ of samples of some species of seabirds (van Franeker et al. 2011). Also, entanglement and ingestion have been reported in $66 \%$ of all species of marine mammals (Kühn et al. 2015). Even though we know from studies that plastic debris can perforate the gut and/or obstruct the passage of food, which may lead to sublethal (e.g., mass loss, reduced growth) and lethal effects (Beck and Barros 1991, Jacobsen et al. 2010, Brandão et al. 2011), it is often difficult to determine whether the plastic in a stranded animal actually caused such impacts.

In other cases, such as "ghost fishing" (the continued catching of organisms by nets and traps that have been lost or abandoned by the fishing industry), many ghost-nets remain active for long periods and are the cause of death of thousands of individuals from many taxa, including invertebrates and vertebrates, some rare and/or endangered (Laist 1987, Good et al. 2010, Gall and Thompson 2015). Nevertheless, it is still not demonstrated that the deaths of these individuals actually cause identifiable ecological impacts (i.e., altered the population or assemblage). Establishing ecological (as opposed to individual) impacts would require that the amounts of mortality due to ghost fishing alone be estimated in relation to the sizes and rates of change in populations.

To determine ecological impacts of debris, it may be difficult to obtain necessary information in many scenarios and for many marine species due to the logistics of sampling and obtaining permits for experimentation (e.g., mammals). Without the appropriate experiments and/or modeling it will be difficult to link the presence of debris to ecological impacts. This problem calls into question the role of certain species of birds and mammals in existing programs of ecological monitoring. Because of the difficulties of experimentation, some of these programs measure contamination rather than ecological impact. Still, for sea birds, some types of manipulative experiments are possible. For marine mammals, laboratory experiments with cell cultures (using the same debris and cell types we have reviewed from the medical literature) may be linked to population models. For ghost fishing data, modeling may be used to determine how the populations might be affected.

Moreover, limitations to experimental design can make it difficult to determine whether marine debris is the cause of ecological impact in the presence of other environmental stressors (e.g., chemical pollutants, overfishing, climatic change). As such, decisions by policy makers will have to be based upon the best available evidence. In some cases, demonstrated impacts at all levels of organization can be used to provide the links to determine how a stressor may disrupt the ecology of the organisms. As has been the case with other forms of contamination leading to pollution, it is important to consider responses across several levels of biological organization to evaluate, interpret and/or predict reliably the net effect of contaminants on wildlife (Underwood and Peterson 1988, Adams et al. 1989, Browne et al. 2015b). Using existing methods, such as "adverse outcome pathways" (Ankley et al. 2010, Kramer et al. 2011), suborganismal impacts from debris can be translated to lethal and sublethal effects on individuals (many of which have been demonstrated) to a quantified effect on the population, species and assemblages to underpin ecological risk assessment and management. Our systematic review synthesizes the existing demonstrated impacts across a wide range of sizes and types of debris and biological levels of organization (e.g., molecular, cellular, organism, and population), providing a useful structure to organize the existing data to be used in such future analyses and identify key uncertainties and priorities for research.

Systematic and critical reviews increase the accessibility of the best available evidence, but also provide a more efficient and less biased platform for decision making (Pullin and Stewart 2006, Mayer-Pinto et al. 2010). Global industries are requesting comprehensive sciencebased policies and enforcement of existing laws to prevent marine debris (Global Plastics Association 2012). Despite clear legal guidelines on what evidence is required, some government agencies and industries (e.g., American Chemistry Council, The Coca-Cola Company, UNEP, USEPA) have formed a Global Partnership on Marine Litter and are requesting additional evidence of ecological harm by marine debris to build effective policies for managing waste (UNEP/NOAA 2011). While we agree that better quality evidence is needed to fill in research gaps at the higher levels of organization to assess the ecological risk and impacts of marine debris, our systematic review found 245 lines of evidence demonstrating valid concerns regarding adverse effects of marine debris and that this persistent and bio-accumulative material causes impacts across 13 levels of organization, including at ecological levels.

Thus, despite the problems and uncertainties in the literature, there appears to be enough evidence for policy makers to recognize the hazards and take a precautionary and/or anti-catastrophe approach (United Nations Environment Programme 1992, Inter-Departmental Liaison Group on Risk Assessment 2002, Sunstein 2005), by beginning to mitigate the problem now before there is any irreversible harm from such pervasive materials. For example, many impacts were associated with plastic 
debris in the form of lost fishing gear or single-use plastic items such as bags and straws. Policy makers can use existing laws designed for responses to similar persistent and bioaccumulative pollutants (i.e., Official Journal of the European Union 2008, USEPA 1980) to help ameliorate problems caused by marine debris.

\section{ACKNOWLEDGMents}

We thank M. G. Chapman, S. D. Gaines, K. L. Law. and A. I. Catarino for reviewing drafts of the manuscript. We are grateful to Whitney Reyes and Rosalyn Lam for helping search the literature, Jim Rigetz for help with Fig. 2, and Anthony Andrady, Francois Galgani, and Ken Donaldson for help with data extraction. This work was conducted within the Marine Debris Working Group at the National Center for Ecological Analysis and Synthesis (NCEAS), University of California, Santa Barbara, with support from Ocean Conservancy.

\section{Literature Cited}

Adams, S. M., K. L. Shepard, M. S. Greeley, B. D. Jimenez, M. G. Ryon, L. R. Shugart, J. F. McCarthy, and D. E. Hinton. 1989. The use of bioindicators for assessing the effects of pollutant stress on fish. Marine Environmental Research 28:459-464.

Ankley, G. T., et al. 2010. Adverse outcome pathways: a conceptual framework to support ecotoxicology research and risk assessment. Environmental Toxicology and Chemistry 29:730-741.

Ashton, K., L. Holmes, and A. Turner. 2010. Association of metals with plastic production pellets in the marine environment. Marine Pollution Bulletin 60:2050-2055.

Barnes, D. K. A., F. Galgani, R. C. Thompson, and M. Barlaz. 2009. Accumulation and fragmentation of plastic debris in global environments. Philosophical Transactions of the Royal Society B 364:1985-1998.

Beck, C. A., and N. B. Barros. 1991. The impact of debris on the Florida manatee. Marine Pollution Bulletin 22:508-510.

Brandão, M. L., K. M. Braga, and J. L. Luque. 2011. Marine debris ingestion by Magellanic penguins, Spheniscus magellanicus(Aves: Sphenisciformes), from the Brazilian coastal zone. Marine Pollution Bulletin 62:2246-2249.

Browne, M. A., A. Dissanayake, T. S. Galloway, D. M. Lowe, and R. C. Thompson. 2008. Ingested microscopic plastic translocates to the circulatory system of the mussel, Mytilus edulis (L.). Environmental Science \& Technology 42:5026-5031.

Browne, M. A., T. S. Galloway, and R. C. Thompson. 2010. Spatial patterns of plastic debris along estuarine shorelines. Environmental Science \& Technology 44:3404-3409.

Browne, M. A., S. J. Niven, T. S. Galloway, S. J. Rowland, and R. C. Thompson. 2013. Microplastic moves pollutants and additives to worms, reducing functions linked to health and biodiversity. Current Biology 23:2388-2392.

Browne, M. A., M. G. Chapman, R. C. Thompson, L. A. Amaral-Zettler, J. Jambeck and N. J. Mallos. 2015a. Spatial and temporal patters of stranded intertidal debris: is there a picture of global change? Environmental Science and Technology 49(12):7082-7094.

Browne, M. A., A. J. Underwood, M. G. Chapman, R. Williams, R. C. Thompson, and J. A. van Franeker. 2015b. Linking effects of anthropogenic debris to ecological impacts. Proceedings of the Royal Society of London B 282:20142929.
Carpenter, E. J., and K. L. Smith. 1972. Plastics on the Sargasso Sea surface. Science 175:1240-1241.

Carson, H. S., S. L. Colbert, M. J. Kaylor, and K. J. McDermid. 2011. Small plastic debris changes water movement and heat transfer through beach sediments. Marine Pollution Bulletin 62:1708-1713.

Choy, A. C., and J. C. Drazen. 2013. Plastic for dinner? Observations of frequent debris ingestion by pelagic predatory fishes from the central North Pacific. Marine Ecology Progress Series 485:155-163.

Cózar, A., F. Echevarria, J. I. Gonzalez-Gordillo, X. Irigoien, B. Ubeda, S. Hernandez-Leon, and A. T. Palma. 2014. Plastic debris in the open ocean. Proceedings of the National Academy of Sciences 111:10239-10244.

Donohue, M. J., R. C. Boland, C. M. Sramek, and G. A. Antonelis. 2001. Derelict fishing gear in the Northwestern Hawaiian Islands: diving surveys and debris removal in 1999 confirm threat to coral reef ecosystems. Marine Pollution Bulletin 12:1301-1312.

Endo, S., R. Takizawa, K. Okuda, H. Takada, K. Chiba, H. Kanehiro, H. Ogi, R. Yamashita, and T. Date. 2005. Concentration of polychlorinated biphenyls (PCBs) in beached resin pellets: variability among individual particles and regional differences. Marine Pollution Bulletin 50:1103-1114.

van Franeker, J. A., et al. 2011. Monitoring plastic ingestion by the northern fulmar Fulmarus glacialis in the North Sea. Environmental Pollution 159:2609-2615.

Galgani, F., et al. 2000. Litter on the sea floor along European coasts. Marine Pollution Bulletin 40:516-527.

Gall, S. C., and R. C. Thompson. 2015. The impact of debris on marine life. Marine Pollution Bulletin 92:170-179.

Global Plastics Association. 2012. Declaration of the Global Plastics Associations for Solutions on Marine Litter. http:// www.marinedebrissolutions.com/Declaration. Last accessed 15 September 2014.

Goldberg, E. D. 1997. Plasticizing the seafloor: an overview. Environmental Science \& Technology 18:195-201.

Good, T. P., J. A. June, M. A. Etnier, and G. Broadhurst. 2010. Derelict fishing nets in Puget Sound and the Northwest Straits: patterns and threats to marine fauna. Marine Pollution Bulletin 60:39-50.

Goodsell, P. J., A. J. Underwood, and M. G. Chapman. 2009. Evidence necessary for taxa to be reliable indicators of environmental conditions or impacts. Marine Pollution Bulletin 58:323-331.

Gregory, M. R. 2009. Environmental implications of plastic debris in marine settings - entanglement, ingestion, smothering, hangers-on, hitch-hiking and alien invasions. Philosophical Transactions of the Royal Society B 364:2013-2025.

Inter-Departmental Liaison Group on Risk Assessment. 2002. The precautionary principle: policy and application. http:// www.hse.gov.uk/aboutus/meetings/committees/ilgra/pppa. pdf. Last accessed 15 September 2014.

Jacobsen, J. K., L. Massey, and F. Gulland. 2010. Fatal ingestion of floating net debris by two sperm whales (Physetermacrocephalus). Marine Pollution Bulletin 60:765-767.

Katsanevakis, S., G. Verriopoulos, A. Nicolaidou, and M. Thessalou-Legaki. 2007. Effect of marine litter on the benthic megafauna of coastal soft bottoms: a manipulative field experiment. Marine Pollution Bulletin 54:771-778.

Kramer, V. J., M. A. Etterson, M. Hecker, C. A. Murphy, G. Roesijadi, D. J. Spade, J. A. Spromberg, M. Wang, and G. T. Ankley. 2011. Adverse outcome pathways and ecological risk assessment: bridging to population-level effects. Environmental Toxicology and Chemistry 30:64-76.

Kühn, S., E. L. Bravo Rebolledo and J. A. Van Franeker. 2015. Deleterious effects of litter on marine life. Pages 75-116 in M. 
Bergmann, L. Gutow, and M. Klages, editors. Marine anthropogenic litter. Springer, Berlin.

Laist, D. W. 1987. Overview of the biological effects of lost and discarded plastic debris in the marine environment. Marine Pollution Bulletin 18:319-326.

Law, K. L., S. Morét-Ferguson, N. A. Maximenko, G. Proskurowski, E. E. Peacock, J. Hafner, and C. M. Reddy. 2010. Plastic accumulation in the North Atlantic subtropical gyre. Science 329:1185-1188.

Mayer-Pinto, M., A. J. Underwood, T. Tolhurst, and R. A. Coleman. 2010. Effects of metals on aquatic assemblages: what do we really know? Journal of Experimental Marine Biology and Ecology 391:1-9.

Moore, E., et al. 2009. Entanglements of marine mammals and seabirds in central California and the north-west coast of the United States 2001-2005. Marine Pollution Bulletin 58:1045-1051.

Murray, F., and P. R. Cowie. 2011. Plastic contamination in the decapod crustacean Nephrops norvegicus (Linnaeus, 1758). Marine Pollution Bulletin 62:1207-1217.

Official Journal of the European Union. 2008. EU Directive 2008/98/EC. http://eurlex.europa.eu/LexUriServ/LexUriServ. do?uri=OJ:L:2008:312:0003:0030:en:PDF. Last accessed 15 September 2014.

Özdilek, H. G., S. Yalçin-Özdilek, F. S. Ozaner, and B. Soenmez. 2006. Impact of accumulated beach litter on Chelonia mydas L. 1758 (Green turtle) hatchlings of the Samandag Coast, Hatay, Turkey. Fresenius Environmental Bulletin 15:95-103.

Pullin, A. S., and G. B. Stewart. 2006. Guidelines for systematic review in conservation and environmental management. Conservation Biology 20:1647-1656.

Rochman, C. M., M. A. Browne, B. S. Halpern, B. T. Hentschel, E. H. Hoh, H. K. Karapanagioti, L. M. Rios-Mendoza, H. Takada, S. Teh, and R. C. Thompson. 2013a. Policy: classify plastic waste as hazardous. Nature 494:169-171.

Rochman, C. M., E. Hoh, T. Kurobe, and S. Teh. 2013b. Ingested plastic transfers contaminants to fish and induces hepatic stress. Scientific Reports 3:3263.

Sunstein, C. R. 2005. Laws of fear: beyond the precautionary principle. Cambridge University Press, Cambridge, UK.
Sutherland, W. J., et al. 2010. A horizon scan of global conservation issues for 2010. Trends in Ecology \& Evolution $25: 1-7$.

Tanaka, K., H. Takada, R. Yamashita, K. Mizukawa, M. Fukuwaka, and Y. Watanuki. 2013. Accumulation of plasticderived chemicals in tissues of seabirds ingesting marine plastics. Marine Pollution Bulletin 69:219-222.

Thompson, R. C., Y. Olsen, R. P. Mitchell, A. Davis, S. J. Rowland, A. W. G. John, D. McGonigle, and A. E. Russell. 2004. Lost at sea: where is all the plastic? Science 304:838-838.

Thompson, R. C., C. J. Moore, F. S. vomSaal and S. H. Swan. 2009. Plastics, the environment and human health: current consensus and future trends. Philosophical Transactions of the Royal Society B 364:2153-2166.

Uhrin, A. V., and J. Schellinger. 2011. Marine debris impacts to a tidal fringing-marsh in North Carolina. Marine Pollution Bulletin 6:2605-2610.

Underwood, A. J., and C. H. Peterson. 1988. Towards an ecological framework for investigating pollution. Marine Ecology Progress Series 46:227-234.

UNEP/NOAA. 2011. The Honolulu strategy: a global framework for prevention and management of marine debris. http://gpa.unep.org/index.php/global-partnership-on-nutrient-management/publications-and-resources/global-partnership-on-marine-litter-gpml/158-honolulu-strategy-final/file. Last accessed 15 September 2014.

United Nations Environment Programme. 1992. Rio declaration on environment and development. http://www.unep.org/ Documents. Multilingual/Default.asp?documentid=78\&articleid $=1163$. Last accessed 15 September 2014.

USEPA. 1980. Comprehensive Environmental Response, Compensation and Liability Act of 1980. http://www.epa.gov/ superfund/policy/cercla.htm. Last accessed 15 September 2014.

Van Cauwenberghe, L., and C. R. Janssen. 2014. Microplastics in bivalves cultured for human consumption. Environmental Pollution 193:65-70.

Zettler, E. R., T. Mincer, and L. A. Amaral-Zettler. 2013. Life in the "plastisphere": microbial communities on plastic marine debris. Environmental Science \& Technology 47:7137-7146.

\section{SUPPORTING INFORMATION}

Additional supporting information may be found in the online version of this article at http://onlinelibrary.wiley.com/ doi/10.1890/14-2070.1/suppinfo 